\title{
UNUSUAL CASE OF ANGIOSARCOMA OF LIVER PRESENTING WITH PULMONARY METASTASIS IN A YOUNG GIRL
}

Daspin $D^{1}$, Tom Aby², Ramalingam Sivaraman ${ }^{3}$, Francis $G^{4}$

${ }_{1}^{1}$ MBBS, D.M.R.D., (D.N.B), Department of Radiology, MIOT International Hospital, Chennai.

${ }^{2}$ MBBS, (D.N.B), Department of Radiology, MIOT International Hospital, Chennai.

${ }_{3}^{3}$ MBBS, D.N.B (RAD), Department of Radiology, MIOT International Hospital, Chennai.

${ }^{4}$ MBBS, D.M.R.D., D.N.B., MNAMS, Department of Radiology, MIOT International Hospital, Chennai.

HOW TO CITE THIS ARTICLE: Daspin D, Aby T, Sivaraman R, et al. Unusual case of angiosarcoma of liver presenting with pulmonary metastasis in a young girl. J. Evolution Med. Dent. Sci. 2017;6(69):4966-4967, DOI: 10.14260/Jemds/2017/1077

\section{PRESENTATION OF CASE}

A 12-year-old female child named Avanika Singh got admitted in our institute with chief complaints of abdominal pain for 3 weeks and haematemesis for 1 week duration. She attained menarche in July 2016, following which she gave history of menorrhagia and was treated with hormonal pills for last week.

\section{CLINICAL DIAGNOSIS}

On examination, she was found to be afebrile with severe pallor and stable parameters. On systemic examination, she was found to have hepatomegaly with severe tenderness. No icterus or pedal oedema noted.

Initial investigations revealed severe anaemia with the haemoglobin of $7 \mathrm{gm} \%$. Other blood parameters are unremarkable. Since she was complaining of severe abdominal pain, the treating physician elsewhere advised for a CT scan of abdomen which revealed hepatomegaly with multiple hypodense lesions in the liver and minimal free fluid in abdomen. She was advised admission in our hospital for further evaluation.

After admission in our institute she was evaluated by a team of doctors including haematologist, pulmonologist and ENT surgeon. Further upper endoscopy was done which revealed swallowed blood from the respiratory tract.

\section{PATHOLOGICAL DISCUSSION}

CECT abdomen revealed multiple heterogeneous lesions of varying sizes in both the lobes of liver. The largest of these lesions measuring $14.5 \mathrm{cms} \times 6.9 \mathrm{cms}$ is noted in the segment 4,5 and 8 of the liver. No evidence of calcifications or fat attenuation noted within the lesion. No evidence of hepatic artery or portal vein invasion noted.

On arterial phase imaging, these lesions show significant enhancement with arterial blush suggestive of neovascularity. Delayed scan imaging showed significant puddling of contrast within the lesion.

Multiple significantly enlarged inhomogeneously enhancing para-aortic, peripancreatic and aorto-caval lymph nodes are also noted. Minimal free fluid was also noted in abdomen.

Financial or Other, Competing Interest: None.

Submission 21-06-2017, Peer Review 15-08-2017,

Acceptance 21-08-2017, Published 28-08-2017.

Corresponding Author:

Dr. Daspin D,

$M B B S, D M R D$, Department of Radiology,

MIOT International Hospital,

Chennai.

E-mail:daspins@yahoo.com

DOI: $10.14260 /$ jemds $/ 2017 / 1077$

(c) $\bigcirc(5)$
CECT chest showed multiple randomly distributed solid and ground glass attenuated nodules in the subpleural and parenchymal location. Few of these solid nodules showed surrounding peripheral ground glass attenuated halo within it.

Based on these findings, possibility of Angiosarcoma with pulmonary metastasis was done.
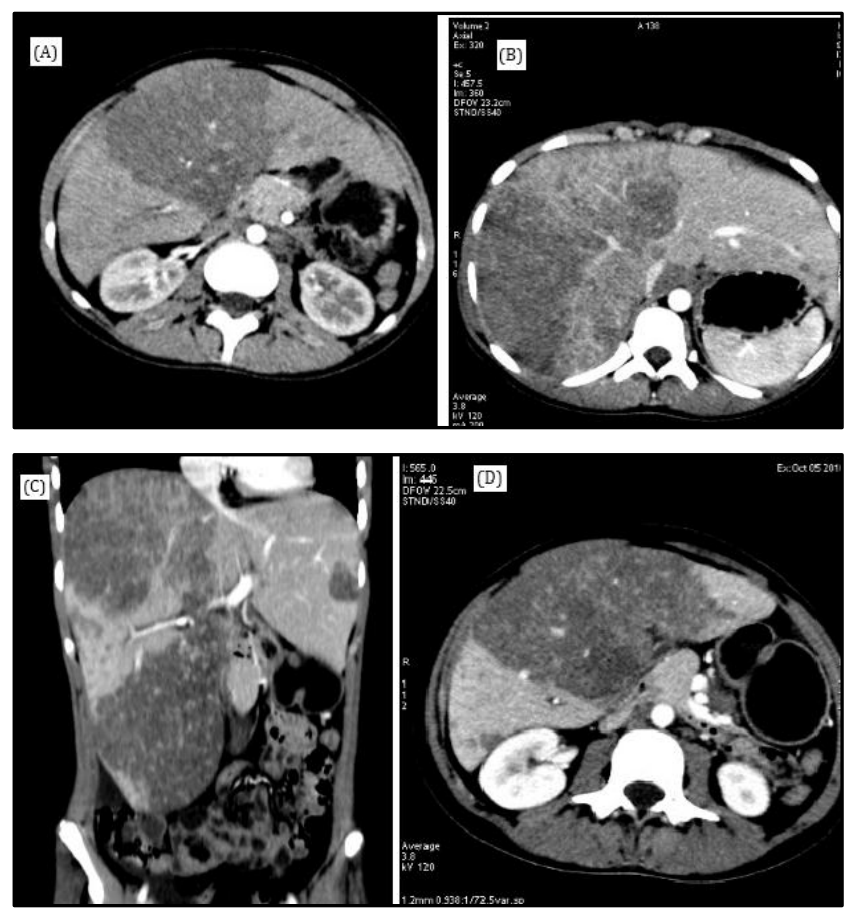

Images (A-D) showing Heterogeneous Lesions in the Liver with Arterial Blush suggestive of Neovascularity

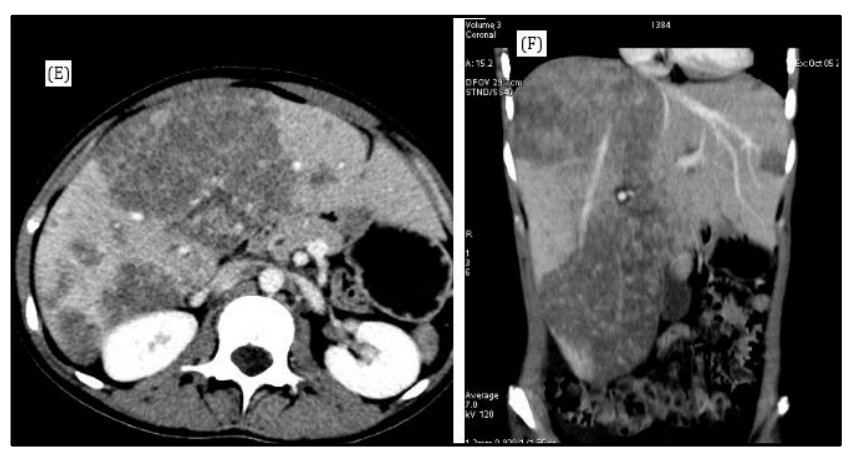

Delayed Images (E, F) showing Pooling of Contrast within the Lesion in the Liver Parenchyma 


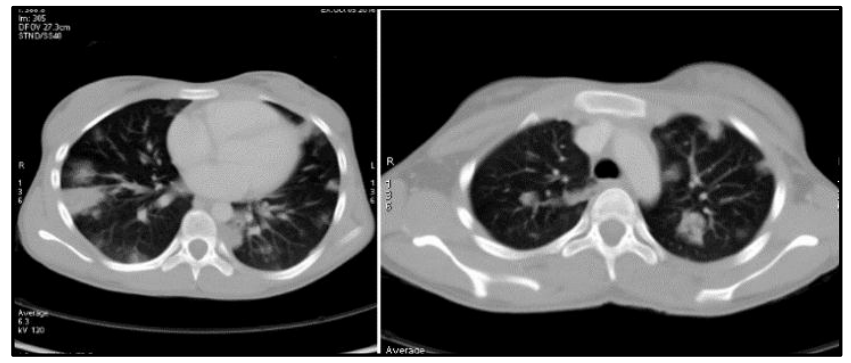

CECT Chest showing Subpleural and Parenchymal Haemorrhagic Metastasis

Liver biopsy was done from the liver lesions under aseptic precautions and sent for histopathological examination. The liver biopsy showed features of Angiosarcoma. Further, the patient was referred to the medical oncologist. He explained the relatives regarding the poor prognosis and advised for the palliative chemotherapy.

The patient had a sudden respiratory discomfort with cardiac arrest and died after 1 month.

\section{DISCUSSION OF MANAGEMENT}

Angiosarcoma is a primary mesenchymal tumour of endothelial cell origin with anastomosing vascular channels. It is predominantly seen in males (males: females 3: 1). Hepatic angiosarcoma is known to have associated with carcinogens including vinyl chloride, thorotrast and arsenic. Liver is an unknown site for its origin. The malignancy has a small association with Von Recklinghausen syndrome and hematochromatosis. ${ }^{(1,2)}$

Of the primary liver cancer angiosarcoma constitutes about 2\%; however, it still ranks the third most common of the liver malignancies. Early metastasis are also a feature of this disease and however high recurrence with metastasis makes it a difficult tumour to treat even with liver transplant. AFP is not elevated in majority of cancer and spontaneous rupture of tumour with associated peritoneal haemorrhage is also a complication. $(3,4)$

On imaging, hepatic angiosarcomas present as multiple lesions, solitary large mass or a mixed type of tumour. Noncontrast scan may show areas of heterogeneity with haemorrhage.

On post-contrast imaging, they usually show early arterial phase enhancement followed by progressive filling of contrast within the lesion. The hypervascular pattern of enhancement is usually different from other vascular tumours in the liver such as hepatomas or hemangiomas. $(5,6)$

Equilibrium and delayed phase imaging shows centripetal filling in of the contrast within the nodules.

MRI shows diffuse hyperintensity with variable ADC values which are higher than the mean seen in other hepatic malignancies, but low ADC values as compared to that seen in benign cysts and hemangiomas.(7) The imaging feature of angiosarcoma with hepatocyte specific contrast, which has an additional advantage for scanning the patient at a delayed interval of 90 minutes is possible. The tumour appeared iso- intense and almost homogeneous to rest of the liver in the delayed hepatocyte specific phase. $(8,9)$

FDG PET imaging is useful in the depiction of distant metastasis, which are usually present at the time of presentation.

\section{CONCLUSION}

Angiosarcoma is a rare mesenchymal tumour of origin. In the current clinical scenario, it can present without the history of carcinogens exposure with which it is known to be associated. It has variable pattern of enhancement with a few salient distinctive imaging points, which should be kept under consideration when reporting atypical hypervascular tumour in the liver.(10,11) FDG PET imaging is useful in the depiction of distant metastasis, which are usually present at the time of presentation.

\section{FINAL DIAGNOSIS}

Angiosarcoma with haemorrhagic lung metastasis.

\section{REFERENCES}

[1] Locker GY, Doroshow JH, Zwelling LA, et al. The clinical features of hepatic angiosarcoma: a report of four cases and a review of the English literature. Medicine (Baltimore) 1979;58(1):48-64.

[2] Kim HR, Rha SY, Cheon SH, et al. Clinical features and treatment outcomes of advanced stage primary hepatic angiosarcoma. Ann Oncol 2009;20(4):780-7.

[3] Young RJ, Brown NJ, Reed MW, et al. Angiosarcoma. Lancet Oncology 2010;11(10):983-91.

[4] Mani H, Thiel VDH. Mesenchymal tumors of the liver. Clin Liver Dis 2001;5(1):219-57.

[5] Buetow PC, Buck JL, Ros PR, et al. Malignant vascular tumours of the liver: radiologic-pathologic correlation. Radiographics 1994;14(1):153-66.

[6] Timaran CH, Grandas OH, Bell JL. Hepatic angiosarcoma: long-term survival after complete surgical removal. Am Surg 2000;66(12):1153-7.

[7] Molina E, Hernandez A. Clinical manifestations of primary hepatic angiosarcoma. Dig Dis Sci 2003;48(4):677-82.

[8] Almogy G, Lieberman S, Gips M, et al. Clinical outcomes of surgical resections for primary liver sarcoma in adults: results from a single centre. Eur J Surg Oncol 2004;30(4):421-7.

[9] Holden CA, Spittle MF, Jones EW. Angiosarcoma of the face and scalp, prognosis and treatment. Cancer 1987;59(5):1046-57.

[10] Maddox JC, Evans HL. Angiosarcoma of skin and soft tissue: a study of forty-four cases. Cancer 1981;48(8):1907-21.

[11] Bruegel M, Muenzel D, Waldt S, et al. Hepatic angiosarcoma: cross-sectional imaging findings in seven patients with emphasis on dynamic contrastenhanced and diffusion-weighted MRI. Abdom Imaging 2013;38(4):745-54. 